\title{
SUSTAINING VALUE MAXIMIZATION IN ENTREPRENEURSHIP THROUGH ETHICS
}

\author{
Dr J G Sheshasaayee and Dr Anitha Ramachander "Raja.K.G ***
}

\begin{abstract}
Market pressures can drive the entrepreneurs acclimatize to unethical practices. When there is tough competition prevailing in the market, the entrepreneur finds loopholes in business ethics to bail them out of the situation. This paper focuses on sustaining value maximization through pragmatic and ethical approaches that are challenges to entrepreneurial leadership. Conformity to all moral and professional principles is ensuring the stakeholders that all decisions and actions are accordance with all applicable laws and regulations and are underpinning the organization's culture and values. Entrepreneurs normally continue to exist with the ever present danger of business failure occurring due to inadequate monetary resources and aggressive competition in the marketplace. Under these conditions, inconsistent precedence arises and the entrepreneur is thus faced with certain predicament. There is a need for understanding ethical practices by integrating them with pragmatic solutions to survive in a challenging environment. This research paper examines how entrepreneurs experience and deal with these impasses. The purpose of this paper is to guide your thinking and action toward creating and sustaining value maximization through an ethical culture. The affiliation between entrepreneurship and ethics has largely been typified as adverse. We develop a conceptual replica assimilating pragmatism with ethics to suggest that sustaining entrepreneurial leadership for value maximization demands ethical action to build legality.
\end{abstract}

\section{Introduction}

In today's competitive global economy, it is imperative to understand the ethical attitudes and standards of entrepreneurs in India. Understanding the factors that contribute to and influence the ethical conduct of entrepreneurs is important for the future of the Indian economic system. These factors become all the more important when operating in an economy that is globally challenging

* Sheshasaayee, J.G., Dean MCA, New Horizon College of Engineering,

Bangalore.Jgsheshu@gmail.com

**Anitha Ramachander, Director, Department of Management Studies,SRN Adarsh College, Bangalore.Anithar72@yahoo.com

${ }^{* \star *}$ Raja.K.G : Asst Professor - Department of Management Studies,SRN Adarsh College,

Bangalore.Rajakg@sify.com 
and competitive. Competition is increasing at a faster pace due to environmental condition, where markets are in constant disequilibrium and change. In such an environment, competitors aggressively disrupt the status quo and seek to change the rules of competition. While current businesses impact the ethical standards used in present business dealings, emerging entrepreneurial companies set the ethical tone for the future economic system of the world. When they develop new strategies and organizational cultures to deal with the external complexity, firms envisage a dilemma. There are strong laws that promote and govern ethical behavior on the part of entrepreneurs; the ethical attitudes are not well understood. There is a need to address the issues that warrants high ethical standards in their internal and external dealings. Entrepreneurs because their business practices more closely reflect their personal values; have higher ethical attitudes than employees. The methodology and results of this study to address these issues are summarized. This is followed by a discussion of the conclusions and recommendations.

\section{Background of the study}

When examining differences in ethical attitudes and behaviors of entrepreneurs, it is important to understand the defining characteristics of entrepreneurs. Their role includes the ability to work out long-term, general strategies and the power to allocate the resources necessary to achieve the desired goals. The power branches out from the equity owned by the entrepreneur. Studying entrepreneurs provides an opportunity for understanding ethics on an individual rather than the collective basis. Entrepreneurs have been found to be both more sensitive to the expectations of society. They are more critical of their performance than the public that gauges them.

\section{Purpose of the study}

The entrepreneur employs personal values to a larger extent and the resulting ethical behavior reflects moral principles, beliefs and behavior. It also provides a more direct reflection of his/her ethical perspectives to issues. Entrepreneurs have different approaches to business in such areas of independent action, innovation, and risk-taking. The key factor in the relationship between economic responsibility and morality is the independent and self centered focus. Entrepreneurs assume financial, psychic, and social risks, and receive the resulting rewards of monetary and personal satisfaction and independence. Entrepreneurs, obtain loans that are secured by their personal property and risk losing a large proportion of their personal wealth. They are risk takers. All this necessitate the need to study the importance of ethics and entrepreneurship.

\section{Scope of Study}

Further research is needed to determine the factors that influence the ethical and entrepreneurs. Perhaps core values implanted by family members, teachers, and mentors early in life determine an entrepreneur's ethical decision-making and standards. Or, perhaps the ethical values and 
behavior are influenced by school curricula, including those found in business schools. It may be that external conditions, such as public versus private ownership, have an overarching role. Future research on entrepreneurial and decision-making should provide insight into not only the decisionmaking process, but also its ethical and economic implications.

\section{Review of Literature}

Hisrich \& Solymossy (1996) highlighted the difficulties of balancing economic expediency with moral principles as studied by some authors in the USA (Benson, 1992; Moore, 1988; Ackoff, 1987). This balancing should become much more difficult for entrepreneurs in the highly unstable environment and without lots of entrepreneurial tradition. The ethics of entrepreneurs should rely more upon their individual or personal views, they could employ as owners-managers their personal values to a much greater extent than managers within large businesses (Humphreys et al., 1993), since they are not constrained by the structure of bureaucratic corporate organizations. Jackal (1988) made the argument about ethical views of managers being affected by a complex interaction between the manager's personal value system and that of upper management (and other stakeholders that might execute some influence on manager's decisions), frequently resulting in manager's ethical decisions being influenced by considerations other than their personal value systems. Entrepreneur's beliefs and behaviors may provide a more direct reflection of ethical perspectives, since they have the power to stick with their individually maintained moral principles. Longenecker \& Schoen (1975) assumed already entrepreneurs displaying different approaches to business in such areas as independent action, innovation, and risk taking than managers in larger organizations. Large companies are more exposed to the social criticism and government regulations and they can afford the costs of socially responsible activities easier; they are more directed to long-term planning, are financially less sensitive, with better developed formal procedures preventing from the fraudulent behavior of employees. The advantages of small businesses should rest with less bureaucratic pressures, the ease to control small number of employees and the direct involvement with the local environment leading to more socially desirable behavior. Three surveys should be mentioned, following the small vs. large business considerations. Longenecker et al. (1989) used sixteen vignettes with of 2.290 respondents. Statistically significant differences occurred on twelve vignettes, with small businessmen being less acceptant of faulty investment advice, favoritism, acquiescing in dangerous design flaws, misleading financial report, misleading advertising, and defending the healthfulness of smoking cigarettes Dunfee et al. (1989) used quite a small survey (62 respondents), with small firms including firms with up to 1.000 employees. They have found managers of larger companies more accessible for briberies and quicker to introduce formal inquiries on sexual harassment, while managers from smaller firms would use insider trading, punish whistle-blowers and refuse a job offer from the competitor while working on a key project for the current employer. Small businesses therefore perform better on the loyalty of employees. Robertson (1991) again used quite high numbers for the size of the firm (small companies up to 2.500 employees). 
She has found that the size of the company had a strong impact on the level of institutionalization of ethical behavior. Larger firms would develop ethical. codes to a significantly larger share, use brochures and video-cassettes to present their business and policy to their employees, involve their legal department in the ethical policy, providing a source of ethical advice to employees, organize workshop on ethics and develop a structured chain of ethical responsibility. However, we might question if the more formal approach could compensate for less personal values involved in ethical decision-making. This study includes the impact of the perception of the lack of ethical conduct by entrepreneurs on the culture and character of a business and the way their stakeholders perceive them. Recent events have confirmed that there are divergences in the way business conducts its affairs and the way that the community perceives business should conduct its dealings. It is imperative to keep in mind that ethics are rules or principles which guide human conduct. Ethics can be described as the application of moral values to business situations.

\section{Methodology}

A survey instrument based on the extant literature, maintaining theoretical grounding and continuity with prior research; allowing the analysis of objective and subjective perspectives; reflecting the likelihood of behavior in actual business situations confronted by entrepreneurs enabling the assessment of potential distortion due to "socially desirable" responses, and developing a questionnaire applicable to various industries and capable of being replicated in differing cultures and economic environments.

For the empirical analysis we used the data-base consisting of representative samples of participation of 82 respondents from the population based on simple random sampling. The sample comprises of small scale entrepreneurs and upcoming business men in the population. The respondents were required to provide their opinion on a 5 point likert scale of agreement, where 1 was strongly disagree and 5 was strongly agree

\section{Analysis and Interpretation}

\section{Identifying the factors of ethical behavior}

\section{KMO and Bartlett's test of sampling adequacy}

The Kaiser Meyer Olkin measure of sampling adequacy was used assess the appropriateness of factor analysis. Table gives the statistics produced by the variables.

Table 1: KMO and Bartlett's test

\begin{tabular}{|l|l|l|}
\hline $\begin{array}{l}\text { KMO measure of sampling } \\
\text { adequacy }\end{array}$ & .793 \\
\hline Bartlett's test of sphericity & Approx. Chi-square & 2780.328 \\
\hline & Sig. & .000 \\
\hline
\end{tabular}

The KMO value is .793 and this is considered to be adequate to proceed with factor analysis of the data. This indicates that there is a high presence of correlation amongst the variables. The Bartlett's test of sphericity is 2780.328 , which is high value, and it is significant at .01 levels. So factor analysis would provide statistically reliable information. 
In table below the information containing all 4 possible factors and their factor loadings are featured. After rotation majority of the variance is explained by factor 1 and 2 and thereafter the following 3 factors increase only by a small percentage of variance explained.

Table: 2 Total Variance Explained

\begin{tabular}{|l|c|c|c|c|c|c|}
\hline Component & \multicolumn{3}{|c|}{ Initial Eigen Values } & \multicolumn{3}{c|}{ Extraction Sums of Squared Loadings } \\
\hline & Total & $\begin{array}{c}\% \text { of } \\
\text { Variance }\end{array}$ & $\begin{array}{c}\text { Cumulative } \\
\%\end{array}$ & Total & $\begin{array}{c}\% \text { of } \\
\text { Variance }\end{array}$ & $\begin{array}{c}\text { Cumulative } \\
\%\end{array}$ \\
\hline 1 & 12.014 & 33.371 & 33.371 & 12.014 & 33.371 & 33.371 \\
\hline 2 & 2.533 & 7.037 & 40.408 & 2.533 & 7.037 & 40.408 \\
\hline 3 & 1.720 & 4.777 & 45.185 & 1.720 & 4.777 & 45.185 \\
\hline 4 & 1.471 & 4.086 & 49.271 & 1.471 & 4.086 & 49.271 \\
\hline
\end{tabular}

Table: 3 Factor Structure

\begin{tabular}{|c|l|c|}
\hline SI. No. & Variable Attributes & Factor Loading \\
\hline & Factor 1 : People and Ethics & \\
\hline 1. & Man is basically good & 7.12 \\
\hline 2. & The average person is more ethical than myself & .684 \\
\hline 3. & $\begin{array}{l}\text { Core values implanted by family members, teachers and mentors early } \\
\text { in life may influence an individual entrepreneur's ethical standards }\end{array}$ & .783 \\
\hline 4. & If something is illegal, then it is ethically wrong to do it & .635 \\
\hline & Factor 2 : Business and Ethics & .622 \\
\hline 5. & Having a prescribed "code of ethics" assist in decision making & .607 \\
\hline 6. & Personal ethics are sacrificed to the goals of business & .629 \\
\hline & Factor 3 : Doing Business & .659 \\
\hline 7. & $\begin{array}{l}\text { Most businesses truly do not care about individual } \\
\text { customer / consumers }\end{array}$ & .564 \\
\hline 8. & $\begin{array}{l}\text { Most businesses generally try to deal with me in a fair way, and } \\
\text { thus, I try to deal in a fair way with them }\end{array}$ & \\
\hline 9. & If you deal honestly with a person he/she will deal honestly with you & .603 \\
\hline & Factor 4 - Business and Government & .566 \\
\hline 10. & Free enterprise is the best form of an economic System & \\
\hline 11. & The government has too many laws regulating business & \\
\hline
\end{tabular}

Source : Primary Data 
Table 4: Affirmative responses of entrepreneurs about ethics and business

\begin{tabular}{|c|c|}
\hline Factors & Mean scores \\
\hline \multicolumn{2}{|l|}{ BUSINESS AND GOVERNMENT } \\
\hline Free enterprise is the best form of an economic System & 3.70 \\
\hline The government has too many laws regulating business & 4.10 \\
\hline \multicolumn{2}{|l|}{ BUSINESS AND ETHICS } \\
\hline Having a prescribed "code of ethics" assist in decision Making & 3.92 \\
\hline Personal ethics are sacrificed to the goals of business & 3.56 \\
\hline \multicolumn{2}{|l|}{ DOING BUSINESS } \\
\hline Most businesses truly do not care about individual customers / consumers & 3.21 \\
\hline $\begin{array}{l}\text { Most businesses generally try to deal with me in a fair way, and thus, I try to } \\
\text { deal in a fair way with them }\end{array}$ & 4.27 \\
\hline If you deal honestly with a person he / she will deal honestly with you & 4.76 \\
\hline \multicolumn{2}{|l|}{ PEOPLE AND ETHICS } \\
\hline Man is bascially good & 4.25 \\
\hline The average person is more ethical than myself & 3.85 \\
\hline $\begin{array}{l}\text { Core values implanted by family members, teachers and mentors early in life } \\
\text { may influence an individual entrepreneur's ethical standards }\end{array}$ & 4.60 \\
\hline If something is illegal, then it is ethically wrong to do it & 4.51 \\
\hline
\end{tabular}

\section{Analyzing the factors}

Not surprisingly, entrepreneurs also had stronger ethical perceptions about their relationship to the business. However, given the relatively higher level of personal discretion available in entrepreneurship, it is noteworthy that a high percentage of entrepreneurs still felt that they had to sacrifice their personal ethics to the goals of their business (3.56). Another perspective was obtained by asking respondents whether a prescribed code of ethics would assist in their decision-making, a significant majority felt that codes would be of assistance (3.92). The entrepreneurs felt that there were too many government laws regulating business a higher percentage of entrepreneurs felt this way (4.10). Similarly, a significantly higher percentage of 
entrepreneurs felt that things that were illegal were also unethical (4.51). When asked to decide on the ethics and legality of various situations, entrepreneurs were slightly more critical.

\section{Un Ethical Codes and Attitudes}

The ethical codes and attitudes of the entrepreneurs were explored from several perspectives. First, let us consider each group's reaction to various business activities. A higher percentage of entrepreneurs felt it was not ethical to use organization services and supplies for personal use (3.97). Similarly, more entrepreneurs felt it was unethical to: Accept or Give gifts / favors in exchange for preferential treatment (3.95). Similar negative feelings were expressed by concerning the efficacy of overstating expense accounts (3.69). Again, a greater percentage of entrepreneurs felt these activities were unethical. Similar results occurred in terms of the unethical nature of: authorizing subordinates to violate company policy (3.52); Hire competitor's employees in order to learn competitor's trade secrets (3.65).

Table.5: The share of respondents evaluating certain type of behavior as unethical, wrong behavior

\begin{tabular}{|l|c|}
\hline \multicolumn{1}{|c|}{ Factors } & Mean score \\
\hline Use of office resources for personal use & 3.97 \\
\hline Overstate expense accounts & 3.69 \\
\hline Accept or Give gifts / favors in exchange for preferential treatment & 3.95 \\
\hline Breaking rules, laws, policies & 3.69 \\
\hline Authorize subordinates to violate company policy & 3.52 \\
\hline Hire competitor's employees in order to learn competitor's trade secrets & 3.65 \\
\hline
\end{tabular}

\section{Conclusions and Recommendations}

The research identified 4 major factors which would influence ethics. Entrepreneurs also had stronger ethical perceptions about their relationship to the business. A high percentage of entrepreneurs still felt that they had to sacrifice their personal ethics to the goals of their business (3.56). A significant majority felt that codes would be of assistance (3.92). The entrepreneurs felt that there were too many government laws regulating business a higher percentage of entrepreneurs felt this way (4.10). Similarly, a significantly higher percentage of entrepreneurs felt that things that were illegal were also unethical (4.51). 
Entrepreneurs consistently demonstrated higher ethical attitudes in the internal dealings of the company such as not taking longer than necessary for a job and not using company resources for personal use. A higher percentage of entrepreneurs felt it was not ethical to use organization services and supplies for personal use (3.97). Similarly, more entrepreneurs felt it was unethical to: Accept or Give gifts / favors in exchange for preferential treatment (3.91). Similar negative feelings were expressed by concerning the efficacy of overstating expense accounts (3.69).

Enlightened value maximization recognizes that communication with and motivation of an organization's managers, employees, and partners is extremely difficult. What this means in practice is that if we tell all participants in an organization that its sole purpose is to maximize value, we would not get maximum value for the organization. Value maximization is not a vision or a strategy or even a purpose, it is the scorecard for the organization. We must give people enough structure to understand what maximizing value means in such a way that they can be guided by it and therefore have a chance to actually achieve it. Adopting value maximization as the scorekeeping measure does nothing to relieve us of the responsibility to do all these things and more in order to survive and dominate our sector of the competitive landscape. As an early stage entrepreneurial company it is never too early to start thinking about and implementing a code of conduct to ensure ethical standards are ingrained into the corporate culture. This ensures that all the process and procedures for a well-managed, investor-owned company are robust and developed. An effective code of ethics...

1 Need to have a Board that comprise of members of repute to advice the functioning of the firm and recognizes students' and industry needs

2 To have an ombudsperson responsibility includes coordinating ethics policies, institutionalizing the code, and who serves as an advocate for employees and board members who report, or

3 who are involved in, an ethical dilemma

4 Is supported by the firms' officers and leaders

5 Is communicated to all members and stakeholders

6 Has training to its members

7 Has a hotline where individuals are encouraged to report ethical misconduct without fear of reprisal.

8 Has sanctions and enforces them and must show stakeholders that violators will be punished.

9 An improved code should attempt to list those behaviors it deems unethical, as well as provide respective punishments for said violations.

Is regularly updated and flexible enough to allow for changes in social norms, and it should be reviewed and updated when necessary.

Has a pledge that members take regularly, including a signed oath as part of membership. 


\section{REFERENCES}

- Ackoff R.L. (1987): Business Ethics and the Entrepreneur. Journal of Business Venturing, 2 (3), pp. 185-191.

- Benson G.L. (1992): Teaching Entrepreneurship Through the Classics. Journal of Applied Business Research, 8 (4), pp. 135-140.

- Bucar, B., R.D. Hisrich and M. Glas (2003) "Ethics and Entrepreneurs An international study", Journal of Business Venturing 18, 261-281.

- Chau, L. L. and Siu, W.: 2000, 'Ethical Decision-Making in Corporate Entrepreneurial Organizations', Journal of Business Ethics 23, 365375.

- Collins, O. and D. G. Moore: 1970, The Organization Makers: A Behavioral Study of Independent Entrepreneurs (Appleton Century Cross, New Corriveau, L.: 1994, 'Entrepreneurs, Growth, and Cycles', Economica 61 (February), 11

- Dunfee T. et al. (1991): Firm Size and Attitudes about Ethics: Some Preliminary Empirical Evidence. In Harvey B., ed., Market Morality and Company Size. Kluwer Academic Publ., London. Pp. 103-117

- Fuxman, L. (1997) "Ethical Dilemmas of Doing Business in Post-Soviet Union Ukraine", Journal of Business Ethics Rousseau, D. 2004b. President's message. Academy of Management News, 35(4): 1-2.

- Hisrich R., E. Solymossy (1996): Entrepreneurial Ethics: The Impact of Accountability and Independence. Cleveland: Case Western Reserve University.

- Humphreys N. et al. (1993): The Ethical decision Making Process of Small Business OwnerManagers and Their Customers. Journal of Small Business Management, 31 (3), pp. 9-22.

- Longenecker J., J. Schoen (1975): The Essence of Entrepreneurship. Journal of Small Business Management, 13(3), pp. 26-32.

- McClelland, D. C.: 1961, The Achieving Society (D.Van Nostrand, New York).

- McGarvey, R. (1994): Do the Right Thing. Entrepreneur, April, pp. 64-65.

- Osborne, R. L.: 1994, 'Second Phase Entrepreneur-ship: Breaking Through the Growth Wall', Business Horizons (JanuaryFebruary), 8086.

- Osborne, R. L.: 1991, 'The Dark Side of the Entrepreneur', Long Range Planning 24, 2631. 
- Payne, S. L. and D. L. Duhon: 1990, 'Hard Time Ethics and the Small Business Entrepreneur', Business Insights 9(2), 2932

- Seib, P., \& Fitzpatrick, K. Public relations ethics. Fort Worth, TX: Harcourt Brace.

- Sharpe, M.L. 1993. Public relations = ethical social behavior. PR Update, April: 3.

- Smith P.L., E.F. Oakley III (1994): A Study of the Ethical Values of Metropolitan and Nonmetropolitan Small Business Owners. Journal of Small Business Management, 32 (4), pp. 17-27 